Menşure Kaya,

Yeliz Irem Tunçel,

Rukiye Neslihan Kuru,

Saadet Menteş,

Süheyla Ünver,

Sabahat Çeken,

Mustafa Ertek

\title{
Onkoloji Hastanesi Yoğun Bakım Ünitesinde Kolistin İlişkili Nefrotoksisitenin Retrospektif Değerlendirilmesi
}

\author{
Retrospective Evaluation of Colistin Associated \\ Nephrotoxicity at Oncology Hospital Intensive \\ Care Unit
}

Geliş Tarihi/Received : 27.03.2014

Kabul Tarihi/Accepted : 16.05.2014

Türk Yoğun Bakım Derneği Dergisi, Galenos Yayınevi tarafından basılmışıtır.

Journal of the Turkish Society of Intensive Care, published by Galenos Publishing.

ISSN: 2146-6416

Sabahat Ceken, Mustafa Ertek,

Dr. Abdurrahman Yurtaslan Ankara Onkoloji Eğitim ve Araștırma Hastanesi, Enfeksiyon Hastalıkları Kliniği,

Ankara, Türkiye

Menşure Kaya (凶), Yeliz Irem Tunçel, Rukiye Neslihan Kuru, Saadet Mentes, Süheyla Ünver,

Dr. Abdurrahman Yurtaslan Ankara Onkoloji Eğitim ve Araştırma Hastanesi, Anesteziyoloji ve

Reanimasyon Kliniği, Ankara, Türkiye

E-posta: mensurekaya@yahoo.com

Tel.: +90 31233609 09/4706
ÖZET Amaç: Çalışmamızın amacı, onkoloji hastanesi yoğun bakım ünitesinde, kolistin tedavisi verilen hastaların retrospektif değerlendirilmesi ile nefrotoksisite oranlarını ve nefrotoksisite gelişimi açısından risk faktörlerini belirlemektir.

Gereç ve Yöntem: Toplam 33 hasta çalışmaya dahil edildi. Birden fazla kolistin kulanımı olan hastalarda yalnızca ilk kullanım verileri değerlendirmeye alındı. Böbrek fonksiyon testleri ve hemodiyaliz intiyaçları kaydedildi. Ayrıca hastaların yaş, cinsiyet, kolistin tedavisi sırasında eş zamanlı kullanılan ilaçlar ile kolistin kullanım süreleri ve toplam kolistin dozları not edildi. Nefrotoksisite değerlendirmesi için RIFLE (risk, hasar, yetmezlik, kayıp ve son dönem böbrek yetmezliği) kriterleri kullanıldı.

Bulgular: Hastaların \%69,7'sinde (23 hasta) nefrotoksisite saptandı. RIFLE sınıflamasına göre nefrotoksisite oranları; risk: \%36,36 hasar: \%15,15 ve yetmezlik: \%18,18 idi. Nefrotoksisite gelişen hastalarda kolistin tedavisinin 5. gününde kreatinin ve kan üre azotu değerlerinin anlamlı olarak yükseldiğ görüldü $(p \leq 0,05)$. Malignite tanısı olan hastalarda nefrotoksisite oranı malignite tanısı olmayanlara göre 5,4 kat daha fazlaydı. Eş zamanlı diüretik, aminoglikozit, vankomisin, karbepenem kullanımı nefrotoksisite riskini arttırmadı.

Sonuç: Çalışmamızda nefrotoksisite oranı literatürdeki oranlardan yüksekti. Altta yatan malign tümör tanısının nefrotoksisite oranını arttırdığını saptadık.

Anahtar Kelimeler: Kolistin, nefrotoksisite, yoğun bakım
SUMMARY Objective: The aim of our study, is to determine the nephrotoxicity rates and risk factors for the development of nephrotoxicity by retrospective evaluation of patients who were given colistin therapy oncology hospital intensive care unit. Material and Method: Total of 33 adult patients were included in the study. Renal function tests and hemodialysis requirements were recorded. In addition, patients age, gender, concurrently used drugs with colistin therapy, duration of colistin therapy and total colistin doses were noted. RIFLE criteria (risk, injury, failure, loss, end-stage kidney disease) were used for evaluation of nephrotoxicity. Results: Nephrotoxicity was observed in $69,7 \%$ of patients (23 patients). According to RIFLE criteria nephrotoxicity rates were; risk $36,36 \%$, injury $15,15 \%$ and failure $18,18 \%$. In patients who developed nephrotoxicity, creatinine and blood urea nitrogen values were observed to rise significantly on the 5 th day of colistin treatment $(p \leq 0,05)$. In patients with malignancy, nephrotoxicity rate was 5.4 times higher than those without the diagnosis of malignancy. Concurrent use of diuretic, aminoglycoside, vancomycin and carbapenem did not increase the risk of nephrotoxicity.

Conclusion: In our study, the rate of nephrotoxicity was higher than those in the literature. We found that underlying malignant tumor diagnosis increases the rate of nephrotoxicity.

Key Words: Colistin, nephrotoxicity, intensive care 


\section{Giriş}

Kolistin, polimiksin grubunda, gram negatif bakterilere karşı etkili polipeptid bir antibiyotiktir $(1,2)$. 1959'da parenteral kullanım sonrası yüksek oranda nefrotoksisite ve nörotoksisite görülmesi ve aminoglikozidlerin kullanıma girmesiyle Kolistinin (Polimiksin E) kullanımı azalmıştır. Ancak günümüzde çoklu ilaca dirençli gram negatif organizmaların artması ile tekrar gündeme gelmiştir. Kolistin ticari olarak kolistin sülfat ve kolistimetat sodyum olarak bulunmaktadır. Kolistimetat sodyum bir ön ilaç olup hidroliz sonrası kolsitin ve metan sülfonat derivelerine dönüşmektedir. Kolistimetat böbrekte elimine olmakta ve üriner ekskresyona uğramaktadır. Kolistin sülfat ise başlıca böbrek dışı yollarla elimine olmaktadır (3).

Kolistine bağlı nefrotoksisite gelişme oranları çeşitli çalışmalarda \%6-\%55 arasında değişmektedir (3-5). Ileri yaş, renal yetmezlik öyküsü, hipoalbüminemi varlığı, kontrast madde kullanımı, kolistinle birlikte NSAl ilaç veya vankomisin, aminoglikozit gibi nefrotoksik ilaçların kullanımı kolistine bağlı nefrotoksisite riskini artıran etkenlerdir (6). Akut böbrek hasarının derecelendirilmesi için sıklıkla RIFLE (risk, injury: hasar, failure: yetmezlik, loss: kayıp, end-stage kidney disease: son dönem böbrek yetmezliği) ve AKIN (acut kidney Injury: akut böbrek hasarı) sınıflamaları kullanılmaktadır $(7,8)$.

Çalışmamızın amacı onkoloji hastanesi yoğun bakımında kolistin kullanılan hastaların retrospektif değerlendirilmesi ile RIFLE kriterlerine göre nefrotoksisite oranlarını ve nefrotoksisite gelişimi açısından risk faktörlerini belirlemektir.

\section{Gereç ve Yöntem}

Çalışmamızda Ankara Onkoloji Eğitim ve Araştırma Hastanesi Anestezi Yoğun Bakım Ünitesi'nde 01 Haziran-31 Aralık 2013 tarihleri arasında takip edilen hastaların verileri, eğitim planlama kurulu onayı alındıktan sonra retrospektif olarak incelendi. Kolistimetat sodyum kullanılan hastalar çalışmaya alınırken, 18 yaş altı hastalar ve kronik böbrek hastalığı öyküsü olan hastalar ve 48 saattten daha kısa süre kolistin kullanılan hastalar çalışmaya dahil edilmedi.

Hastaların verilerine klinik veri tabanı, hasta dosyaları ve yoğun bakım izlem formları taranarak ulaşıldı. Hastaların tanıları ve yoğun bakıma kabul nedenleri, yaş, cinsiyet, enfeksiyon yeri ve etken mikroorganizma verileri kaydedildi. Ayrıca mekanik ventilasyon ihtiyaçları ve inotrop gereksinimi not edildi.

Tekrarlayan kolistin kullanımı tespit edilen hastalarda yalnızca ilk kullanım verileri, böbrek fonksiyon testleri (kan üre azotu (BUN) ve kreatinin değerleri), hemodiyaliz ihtiyaçları kaydedildi. Eş zamanlı vankomisin, aminoglikozit, karbapenem, diüretik kullanımı ile günlük doz ve böbrek yetmezliğinin geliştiği toplam kolistin dozları not edildi. Nefrotoksisite değerlendirmesi için RIFLE kriterleri kullanılı (Tablo 1).
İstatistiksel analiz SPSS 16 programı ile yapıldı. Normal dağılım gösteren verilerin analizi için student t test (ortalama 土 standat sapma), normal dağılım olmayan gruplarda Mann Whitney $U$ testi (ortanca (minimum-maksimum), nominal veriler için ki kare analizleri yapıldı. Nefrotoksisite ile ilişkili faktörlerin analizi için regresyon analizi kullanıldı. Yaş ve nefrotoksisite arasındaki ilişki Pearson korelayon analizi ile test edildi. $P<0,05$ anlamlı kabul edildi ve tahmini rölatif risk= odds ratio 'RR' ve güven aralığı şeklinde verildi.

\section{Bulgular}

Çalışmaya toplam 33 hasta dahil edildi. Bu hastaların 24'ünde malignite tanısı vardı. Hastaların \%69,7'sinde $(n=23)$ nefrotoksisite saptandı. Bu hastaların \%21,7'sinde kolistin kullanımına, nefrotoksisite nedeniyle son verildi. RIFLE sınıflamasına göre nefrotoksisite oranları; risk: \%36,3, hasar: \%15,1 ve yetmezlik: \%18,1 idi (Tablo 2). Nefrotoksisite gelişen hastalarda kreatinin ve BUN değerlerinin kolistin tedavisinin 5. gününde nefrotoksisite gelişmeyen hastaların değerlerine göre anlamlı olarak yükseldiği görüldü $(p \leq 0,05)$. Nefrotoksisite gelişen grupta 4. günden itibaren kreatinin seviyesi bazal değere göre anlamlı derecede yüksekti $(p=0,02)$. Bu esnada hastaların santral venöz basınç değerleri nefrotoksiste gelişen hastalarda 9 (7-13) ve nefrotoksisite gelişmeyen hastalarda 8,5 (6-10) olarak ölçüldü $(p=0,08)$. Kolistin tedavisinin ilk 7 gününde, hastaların günlük verilen sıvı miktarı nefrotoksisite gelişen grupta

\begin{tabular}{|c|c|c|}
\hline Kısaltma & $\begin{array}{l}\text { GFH veya [kreatinin] } \\
\text { serum kriteri }\end{array}$ & İdrar miktarı kriteri \\
\hline R (Risk) & Kreatinin $\times 1,5$ & 6 saattir, $<0,5 \mathrm{ml} / \mathrm{kg} / \mathrm{saat}$ \\
\hline I (Injury: hasar) & Kreatinin $\times 2$ & 12 saattir, $<0,5 \mathrm{ml} / \mathrm{kg} / \mathrm{saat}$ \\
\hline \multirow{2}{*}{$\begin{array}{l}\text { F (Failure: } \\
\text { yetersizlik) }\end{array}$} & \multirow{2}{*}{ Kreatinin $\times 3$} & 24 saattir, $<0,3 \mathrm{ml} / \mathrm{kg} / \mathrm{saat}$ \\
\hline & & Veya 12 saattir anüri \\
\hline L (Loss: kayıp) & \multicolumn{2}{|c|}{4 haftadır kalıı böbrek yetmezliği olması } \\
\hline $\begin{array}{l}\text { E (End-stage } \\
\text { renal disease: } \\
\text { son dönem } \\
\text { böbrek } \\
\text { yetmezliği) }\end{array}$ & \multicolumn{2}{|c|}{3 aydan daha fazladır böbrek yetmezliği olması } \\
\hline
\end{tabular}

\begin{tabular}{ll}
\hline \multicolumn{2}{l}{ Tablo 2. RiFLE sınflamasına göre nefrotoksisite oranları } \\
\hline Kriter & Hasta sayısı $(\mathbf{n}=\mathbf{3 3}) \%$ \\
\hline Risk yok & $\% 30,30(\mathrm{n}=10)$ \\
Risk & $\% 36,36(\mathrm{n}=12)$ \\
Hasar & $\% 15,15(\mathrm{n}=5)$ \\
Yetmezlik & $\% 18,18(\mathrm{n}=6)$ \\
\hline
\end{tabular}

Veriler \% ve hasta sayısı olarak verildi. 
$3472,9 \pm 1079,9 \mathrm{ml} /$ gün ve nefrotoksisite gelişmeyen hastalarda $3090,2 \pm 520,3 \mathrm{ml} / \mathrm{gün}(\mathrm{p}=0,465)$ olup sıvı dengesi nefrotoksisite gelişen grupta $963 \pm 489 \mathrm{ml} /$ gün ve nefrotoksisite gelişmeyen

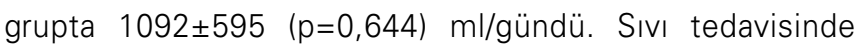
kristaloid solüsyonlar kullanıldı. 7 hastada human albümin ve 4 hastada kolloid solüsyonların gerektiğinde sıvı tedavisine eklendiği saptandı (Grafik 1, 2). Nefrotoksisite gelişen hastaların yaş ortalaması, nefrotoksisite saptanmayanlara göre istatistiksel olarak anlamlı olmamakla beraber daha yüksekti $(64,6 \pm 13,7$ ve $53 \pm 20,7$ ve $p=0,06)$. Kolistin kullanım günü nefrotoksisite gelişen ve gelişmeyen hastalarda benzerdi (Tablo 3).

Kanser tanısı olan hastalarda nefrotoksisite gelişme sıklı̆ı daha yüksekti $(p=0,032)$. Malignite nefrotoksisite gelişimini artıran bir faktör olarak saptandı $(p=0,033)$. Nefrotoksisite gelişen hastalardaki mortalite oranı gelişmeyen gruba göre anlamlı oranda daha yüksekti $(p=0,012)$ (Tablo 3). Eş zamanlı diüretik, aminoglikozit, vankomisin, karbapenem kullanımı ile nefrotoksisite gelişimi arasında ilişki bulunmadı (Tablo 4).

Mekanik ventilasyon ve inotropik destek kullanımı nefrotoksisite gelişen grupta daha yüksekti (Tablo 3). Cinsiyet, nefrotoksisite gelişimi açısından bir risk faktörü olarak saptanmadı (Tablo 4). Nefrotoksisite gelişen hastaların \%47,8'ine hemodiyaliz $\% 8,6$ sına renal replasman tedavisi uygulandı.

Postoperatif hastaların 7'si solid organ tümörü nedeniyle, 5 'i benign nedenlerle opere edilen hastalardı. Postoperatif 12 hastanın 9'unda nefrotoksisite mevcuttu. Hematolojik malignensili 6 hasta ise kemoterapi tedavisi almaktaydı ve ikisinde nefrotoksisite saptandı (Tablo 5). Hastaların hematolojik parametreleri ve aldıkları tedavi Tablo 6 'da verildi.

Hastaların 14'üne bakteriyemi, 12'sine pnömoni, 7'sine üriner enfeksiyon tanısı ile kolistin tedavisi başlanmıştı. Üriner enfeksiyonlu hastalara $(\% 14,2)$ göre bakteriyemili $(\% 42,8)$ ve

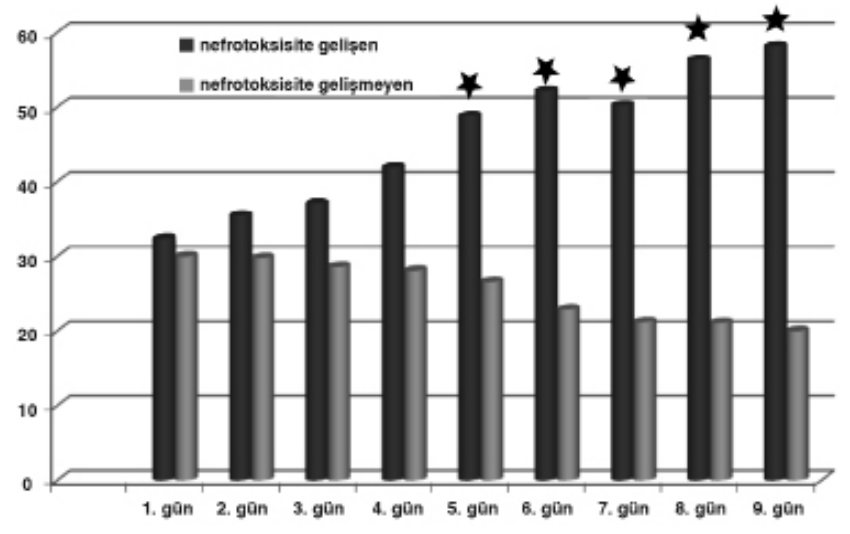

Grafik 1. Hastaların BUN değerleri (BUN: kan üre azotu) $\left({ }^{*} p<0,05\right.$ nefrotoksisite gelişen hastaların BUN değerleri nefrotoksisite gelişmeyenlere göre anlamlı yüksekti)

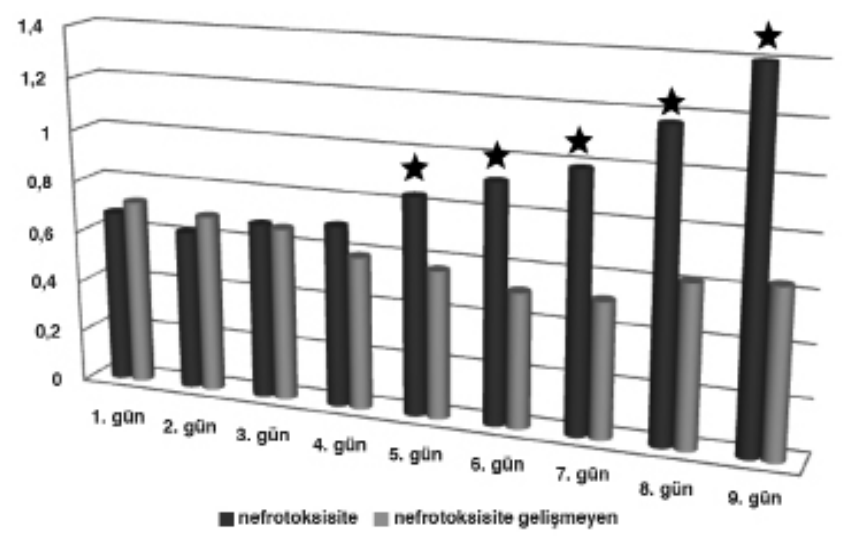

Grafik 2. Kreatinin değerleri ( ${ }^{*} p<0,05$ nefrotoksisite gelişen hastaların kreatinin değerleri nefrotoksisite gelişmeyenlere göre anlamlı oranda yüksekti)

\begin{tabular}{lllll}
\hline Tablo 3. Hastaların demografik ve klinik özellikleri & & & \\
\hline & $\begin{array}{l}\text { Tüm hastalar } \\
(\mathbf{n}=\mathbf{3 3})\end{array}$ & $\begin{array}{l}\text { Nefrotoksisite gelişen } \\
\text { hastalar (n=23) }\end{array}$ & $\begin{array}{l}\text { Nefrotoksisiste gelişmeyen } \\
\text { hastalar (n=10) }\end{array}$ & p değeri \\
\hline Yaş (yll) & $61,1 \pm 16,7$ & $64,6 \pm 13,7$ & $53 \pm 20,7$ & 0,064 \\
Cinsiyet(K/E) & $15 / 18$ & $9 / 14$ & $6 / 4$ & 0,269 \\
Başlangıç kreatinin seviyesi & $0,6(0,4-2,5)$ & $0,6(0,4-2,5)$ & $0,7(0,4-2,1)$ & 0,557 \\
Başlangıç BUN seviyesi & $31,6 \pm 19,7$ & $32,4 \pm 19,7$ & $30 \pm 20,8$ & 0,751 \\
Tedavi süresi (gün) & $28,1 \pm 14,9$ & $30 \pm 15,4$ & $23,9 \pm 13,4$ & 0,289 \\
Kolistin kullanım süresi (gün) & $12,2 \pm 3,2$ & $11,7 \pm 3,3$ & $12,5 \pm 3,1$ & 0,832 \\
Total kolistin dozu mg & $4488 \pm 1307$ & $4296 \pm 1286$ & $4930 \pm 1312$ & 0,205 \\
Mortalite $(n, \%)$ & $20(\% 60,6)$ & $17(\% 73,9)$ & $3(\% 30)$ & 0,012 \\
MV ihtiyacı $(n, \%)$ & $31(\% 93,9)$ & $23(\% 100)$ & $8(\% 80)$ & 0,027 \\
İnotrop ihtiyacı (n,\%) & $20(\% 60,6)$ & $17(\% 73,9)$ & $3(\% 30)$ & 0,018 \\
Malignite tanıı olan (n,\%) & $22(\% 66,6)$ & $18(\% 78,2)$ & $4(\% 40)$ & 0,003 \\
Malignite tanııı olmayan $(n, \%)$ & $11(\% 47,8)$ & $5(\% 45,4)$ & $6(\% 54,5)$ & 0,763 \\
\hline
\end{tabular}

Veriler hasta sayısı (n) \%, Ortalama \pm Standart sapma, Ortanca (minimum-maksimum) olarak verildi. (BUN: kan üre azotu, MV: mekanik ventilasyon) 


\begin{tabular}{|c|c|c|c|c|c|}
\hline Eş zamanlı ilaç kullanımı & $\begin{array}{l}\text { Tüm hastalar } \\
(n=33)\end{array}$ & $\begin{array}{l}\text { Nefrotoksisite gelişen } \\
(n=23)\end{array}$ & $\begin{array}{l}\text { Nefrotoksisiste } \\
\text { gelişmeyen }(n=10)\end{array}$ & p değeri & RR (\%95 GA) \\
\hline Vankomisin & 3 & 2 & 1 & 0,908 & $0,85(0,06-10,69)$ \\
\hline Aminoglikozit & 1 & 1 & 0 & 0,518 & $0,95(0,87-1,04)$ \\
\hline Karbapenem & 22 & 15 & 7 & 0,797 & $0,80(0,16-3,98)$ \\
\hline Diüretik & 25 & 16 & 9 & 0,220 & $0,25(0,02-2,40)$ \\
\hline Yaş (yıl) & $61,1 \pm 16,7$ & $64,6 \pm 13,7$ & $53 \pm 20,7$ & 0,064 & \\
\hline Tanı (malign/benign) & $22 / 11$ & $18 / 5$ & $4 / 6$ & 0,032 & $5,4(1,08-26,93)$ \\
\hline
\end{tabular}

Veriler hasta sayısı (n), Ort \pm SS (ortalama \pm standart sapma), tahmini rölatif risk: odds ratio 'RR' ve GA: güven aralığı olarak verilmiştir.

\begin{tabular}{|c|c|c|c|}
\hline Hasta tanıları & $\begin{array}{l}\text { Tüm } \\
\text { hastalar } \\
(n=33)\end{array}$ & $\begin{array}{l}\text { Nefrotoksisite } \\
\text { gelişen }(n=23)\end{array}$ & $\begin{array}{l}\text { Nefrotoksisiste } \\
\text { gelişmeyen } \\
(n=10)\end{array}$ \\
\hline Solid Tümör & 16 & 16 & 0 \\
\hline Akciğer karsinomu & 4 & 4 & \\
\hline Özefagus karsinomu & 2 & 2 & \\
\hline Kolon karsinomu & 2 & 2 & \\
\hline Mide karsinomu & 2 & 2 & \\
\hline Nazofarenks karsinomu & 2 & 2 & \\
\hline Meme karsinomu & 1 & 1 & \\
\hline Prostat karsinomu & 1 & 1 & \\
\hline $\begin{array}{l}\text { Endometrium } \\
\text { karsinomu }\end{array}$ & 1 & 1 & \\
\hline Mesane karsinomu & 1 & 1 & \\
\hline Hematolojik tümör & 6 & 2 & 4 \\
\hline Lenfoma & 3 & 1 & 2 \\
\hline Lösemi & 3 & 1 & 2 \\
\hline Alzheimer & 2 & 0 & 2 \\
\hline Ortopedik cerrahi & 5 & 4 & 1 \\
\hline Gonartroz & 2 & 1 & 1 \\
\hline Femur kırı̆̆ı & 2 & 2 & 0 \\
\hline Artrodez & 1 & 1 & 0 \\
\hline ALS & 2 & 0 & 2 \\
\hline Aspirasyon & 2 & 1 & 1 \\
\hline
\end{tabular}

ALS: amyotrofik lateral skleroz

pnömonili hastalarda $(\% 33,3)$ kolistin tedavisine cevap daha yüksek bulundu ( $\mathrm{p}=0,001)$.

En sık izole edilen mikroorganizmalar ise Acinetobacter Baumannii $(\% 69,6)$, Staf Epidermitis $(\% 18,1)$, C. Albikans $(\% 21,2)$, P. Aeruginosa $(\% 9)$ ve Klebsiella $(\% 8,6)$ idi. Hastaların $\% 42,4$ 'ünde polimikrobiyal enfeksiyon mevcuttu.
Tablo 6. Hastaların hematolojik parametreleri ve yoğun bakıma kabul sırasındaki tedavileri ( $\mathrm{n}$, hasta sayısı)

\begin{tabular}{llll}
\hline & $\begin{array}{l}\text { Tüm } \\
\text { hastalar } \\
\text { (n=33) }\end{array}$ & $\begin{array}{l}\text { Nefrotoksisite } \\
\text { gelişen } \\
\text { (n=23) }\end{array}$ & $\begin{array}{l}\text { Nefrotoksisite } \\
\text { gelişmeyen } \\
\text { (n=10) }\end{array}$ \\
\hline $\begin{array}{l}\text { Hematolojik } \\
\text { parametreler }\end{array}$ & & & \\
Normal lökosit & 17 & 12 & 5 \\
Lökositoz & 13 & 10 & 3 \\
Pansitopeni & 2 & 0 & 2 \\
Nötropeni & 1 & 1 & 0 \\
Yoğun bakıma kabul & & & \\
sırasında aldıkları tedavi & & & 4 \\
Kemoterapi & 7 & 3 & 0 \\
Radyoterapi & 2 & 2 & 3 \\
Postoperatif hasta & 12 & 9 & 3 \\
Tedavi almayan & 12 & 9 & \\
\hline Veriler hasta sayısı olarak verimiştir. & &
\end{tabular}

\section{Tartışma}

Çalışmamızda genel nefrotoksisite oranı $(\% 69,7)$ literatürdeki oranlardan yüksek bulundu. Malignite tanısı olanlarda nefrotoksisite oranının daha yüksek olduğu saptandı. Son yıllarda çoklu ilaç direnci bulunan gramnegatif bakteriler ile oluşan infeksiyonların sıklığında artış ve tedavilerinde yaşanan sorunlar, nefrotoksisite nedeni ile gözden düşen kolistinlerin yoğun bakımlarda kullanımında artışa sebep olmuştur. Bu nedenle çoklu ilaç direnci bulunan mikroorganizmalar (Acinetobacter baumannii, Pseudomonas aeruginosa, Klebsiella pneumoniae) ile oluşan infeksiyonlarda ve özellikle de kolistin dışındaki diğer antibiyotiklere direnç varlığında kullanılması önerilmektedir $(9,10)$. Kolistinin böbrek atıımı sırasında, tübüler reabsorpsiyona uğrayarak konsantrasyonu artmakta ve renal proksimal tübül hasarı görülmektedir (6). Hem nefrotoksisite hem de nörotoksisite gelişminin doza bağımlı ve geri dönüşümlü olduğu bildirilmiştir $(5,9,10,11,12)$. Kolistine bağlı nefrotoksisite çoğunlukla ilk 
beş gün içinde gelişmektedir $(11,12)$. Çalışmamızda da 5 . günden itibaren BUN ve kreatinin değerlerinin başlangıç değerine göre anlamlı olarak arttığı gözlenmiştir.

Carlos ve Burdmann'a ait derlemede ise kolistine bağlı nefrotoksisite gelişme sıklığı \%15-\%55 olarak verilmiştir (1). Hartzel ve ark.'nın yaptığı 66 hastayı kapsayan kolistine bağlı yan etki çalışmasında nefrotoksisite oranı \%45,4 olarak bildirilmiştir (5). Bu çalışmadaki hasta grubu daha önce bilinen bir sağlık problemi olmayan, genç hastaları (yaş ortalaması $27 \pm 12)$ kapsamaktadır. Kwon ve ark.'nın çalışmasında ise hastaların \%53,5'inde (71 hastanın 38'inde) kolistine bağlı nefrotoksisite gözlenmiş̧ir (13). Bu çalışmada birlikte kalsinörin inhibitörlerinin kullanılmasının, erkek cinsiyet, hipoalbuminemi ve hiperbillüribineminin kolistin kullanımına bağlı akut böbrek hasarı için bağımsız risk faktörü olduğunu bildirmişlerdir. Ayrıca Hartzel'in çalışmasındaki hastalara göre yaş ortalamaları daha yüksek ve renal toksisite için predispozan komorbiditeye sahip hastalardı. Kanser hastalarında Psödomanas enfeksiyonu tedavisinde kolistinin etkinliğinin değerlendirildiği bir çalışmada ise hastaların \%23'ünde kolistine bağlı nefrotoksisite gözlenmiştir (14). Bu çalışmadaki kolistin verilen hastaların 24'ü hematolojik malignite 7'si solid tümör nedeniyle takip edilen, ve yoğun bakım ihtiyacı olmayıp kliniklerde tedavi edilen hastalardı (14). Averbuch ve ark. hematolojik malignite tanısı ve hematopoetik kök hücre transplantasyonu yapılan 29 hastada kolistine bağlı nefrotoksisite oranını \% 10,5 olarak bildirmişlerdir (15). Intravenöz kolistin ile tedavinin, hematolojik malignite tanısı ve hematopoetik kök hücre transplantasyonu yapılan hastalar için nispeten güvenli olduğunu belirtmişlerdir. Bizim çalışmamızdaki hastalar da yoğun bakımda izlenen ve komorbiditesi fazla olan olgulardan oluşmaktaydı. Hematolojik maligniteli hastalardaki nefrotoksisite \%8,69 iken solid tümör nedeniyle takip edilen hastalarda bu oran $\% 69,5$ olarak saptandı. Malignite tanısı olan tüm hastalarda nefrotoksisite oranı, malignite tanısı olmayanlara göre 5,4 kat daha yüksekti. Çalışmamızda, kanser tanısı olan hastalarda primer böbrek tutulumu mevcut değildi. Ancak kanser tedavisi için sitotoksik ilaçların kullanıldığı, enfeksiyon riski yüksek, hipoalbüminemisi olan veya kemik iliği transplantasyonu uygulanmış hastalardı. $\mathrm{Bu}$ nedenle, çalışma grubumuzdaki hasta özelliklerinin yüksek nefrotoksisite insidansına katkıda bulunduğunu düşünmekteyiz. Çalışmalarda bildirilen kolistine bağlı nefrotoksisite oranlarının farklı olması, böbrek yetmezliğinin tanısı için farklı kriterler kullanılması ve farklı hasta gruplarının değerlendirilmesinden kaynaklanabilir.
Kanser hastalarında tedavi edici ajanların gelişmesi ile birlikte morbidite ve mortalite oranları önemli ölçüde azalmış, ancak hastaların yoğun bakım ünitesine intiyaçları artmıştır. Tedavide kullanılan sitotoksik ajanlar, diğer potansiyel nefrotoksinler, enfeksiyon riski ve sepsis, tümör lizis sendromu ve kemik iliği transplantasyonu akut böbrek hasarı için risk oluşturmaktadır. Ayrıca kanserin kendisi de böbreği metastaz veya infiltrasyon yolu ile etkileyebilir (1618). Kanser tanısı mevcut olan yoğun bakım hastalarında akut böbrek fonksiyon bozukluğu gelişme sıklığı \%12-\%49 olarak bildirilmiştir (18). Genellikle çoklu organ yetmezliği ile birliktedir ve mortalite $\% 72-\% 85$ gibi yüksek orandadır (18). Çalışmamızda genel mortalite oranı \%60,6 iken nefrotoksisite gelişen hasta grubunda mortalite \%73,9 oranındaydı. Hastalarımızdaki polimikrobiyal enfeksiyon ve malignite varlığı prognozu etkilemektedir.

Çalışmalarda, ileri yaş, kolistin ile birlikte vankomisin, amioglikozit, karbapenem, diüretik ve NSAl gibi ilaçların kullanılması, kontrast ajanlar, kolistin kullanım süresi ve dozunun kolistine bağlı nefrotoksisite gelişmesinde risk faktörü olduğu gösterilmiştir $(6,11,19)$. Çalışmamızda nefrotoksisite gelişen hasta grubunda yaş ortalaması daha yüksek olmakla birlikte nefrotoksisite için risk faktörü olarak saptanmadı. Eş zamanlı kullanılan aminoglikozit, vankomisin, karbapenem ve diüretiklerin nefrotoksisite gelişmesinde bir risk faktörü olduğu gösterilemedi. Ancak nefrotoksisite gelişen hastalarda, daha fazla diüretik kullanımı mevcuttu.

Kolistin tedavisi sırasında sıvı dengesi önemlidir. Yoğun bakım ünitemizde, hastaların aldığı-çıkardığı takibi, santral venöz basınç monitörizasyonu, kreatinin klirensi ve BUN değerleri ile serum elektrolit değerleri nefroloji ünitesi ile birlikte değerlendirilerek sıvı tedavisi düzenlenmektedir. $\mathrm{Bu}$ nedenle hastalarda yeterli hidrasyon sağlandığını düşünmekteyiz.

\section{Sonuç}

Nefrotoksisite kolistin kullanımının önemli bir yan etkisidir. Özellikle maliginite tanısı olan hastalar kolistine bağlı yan etkiler açısından ilk günden itibaren daha dikkatle izlenmelidir. Solid veya hematolojik malignite mevcudiyetinde kolistine bağlı nefrotoksisite sıklığını ve nefrotoksisite gelişimi arasındaki ilişkiyi inceleyen prospektif çalışmaların yapılması gerektiğini düşünmekteyiz.

\section{Çıkar Çatışması}

Yazarlar herhangi bir çıkar çatışması bildirmemișlerdir. 


\section{Kaynaklar}

1. Carlos Alberto Caldeira Mendes, Emmanuel A Burdmann. Polymyxins - A review focusing on their nephrotoxicity Rev Assoc Med Bras 2010;56:752-8.

2. Yahav D, Farbman L, Leibovici L, Paul M. Colistin: new lessons on an old antibiotics. Clin Microbiol Infect 2012;18:18-29.

3. Falagas ME, Kasiakou SK. Toxicity of polymyxins: a systematic review of the evidence from old and recent studies. Crit Care 2006;10:27.

4. Lim LM1, Ly N, Anderson D, Yang JC, Macander L, Jarkowski A 3rd, et al. Resurgence of colistin: a review of resistance, toxicity, pharma $\neg$ codynamics, and dosing. Pharmacotherapy 2010;30:1279-91.

5. Hartzell JD1, Neff R, Ake J, Howard R, Olson S, Paolino K, et al. Nephrotoxicity Associated with Intravenous Colistin (Colistimethate Sodium) Treatment at a Tertiary Care Medical Center. Clinical Infectious Diseases 2009;48:1724-8.

6. Mert A. Kolistin toksisitesi. Ankem Derg 2012;26:22-6.

7. Schrier RW, Wang W, Poole B, Mitra A. Acute renal failure: definitions, diagnosis, pathogenesis, and therapy. J Clin Invest 2004;114:5-14
8. Hoste EA, Kellum JA. RIFLE criteria provide robust assessment of kidney dysfunction and correlate with hospital mortality. Critic Care Med 2006;34:20167.

9. Giamarellou H. Multidrug-resistant gram-negative bacteria: how to treat and for how long. Int J Antimicrob Agents 2010;36:50-4.

10. Pintado V1, San Miguel LG, Grill F, Mejía B, Cobo J, Fortún J, et al. Intravenous colistin sulphomethate sodium for therapy of infections due to multidrugresistant gram-negative bacteria. J Infect 2008;56:185-90.

11. Pogue JM1, Lee J, Marchaim D, Yee V, Zhao JJ, Chopra T, et al. Incidence of and Risk Factors for Colistin-Associated Nephrotoxicity in a Large Academic Health System. Clinical Infectious Diseases 2011;53:879-84.

12. Deryke CA, Crawford AJ, Uddin N, Wallace MR. Colistin dosing and nephrotoxicity in a large community teaching hospital. Antimicrob Agents Chemother 2010;54:4503-5.

13. Kwon JA, Lee JE, Huh W, Peck KR, Kim YG, Kim DJ, et al. Predictors ofacute kidney injury associated with intravenous colistin treatment. Int J Antimicrob Agents 2010;35:473-7.
14. Hachem RY1, Chemaly RF, Ahmar CA, Jiang Y, Boktour MR, Rjaili GA, et al. Colistin Is Effective in Treatment of Infections Caused by Multidrug-Resistant Pseudomonas aeruginosa in Cancer Patients. Antimicrob. Agents Chemother 2007:51:1905-11.

15. Averbuch D, Horwitz E, Strahilevitz J, Stepensky P, Goldschmidt N, Gatt $\mathrm{ME}$, et al. Colistin is relatively safe in hematological malignancies and hematopoietic stem cell transplantation patients. Infection 2013;41:991-7.

16. EREN E, ATA A, ARICAN A. Kanser Tedavisinde Kullanılan llaçlar Ve Nefrotoksisite. DEÜ Tıp Fak Dergisi 2012;26:229-35.

17. Norbert Lameire. Nephrotoxicity of recent anti-cancer agents. Clin Kidney J 2013;26:1-12.

18. Darmon M1, Ciroldi M, Thiery G, Schlemmer B, Azoulay E. Clinical review: Specific aspects of acute renal failure in cancer patients. Critical Care 2006;10:211-8

19. Ingram PR, Lye DC, Tambyah PA, Goh WP, Tam VH, Fisher DA. Risk factors for nephrotoxicity associated with continuous vancomycin infusion in outpatient parenteral antibiotic therapy. J Antimicrob Chemother 2008;62:168-71. 